\title{
The students' acceptance of learning management systems in Saudi Arabian Universities
}

\author{
Mutasem K. Alsmadi \\ Department of Management Information Systems, College of Applied Studies and Community Service, \\ Imam Abdulrahman Bin Faisal University, Saudi Arabia
}

\begin{tabular}{l} 
Article Info \\
\hline Article history: \\
Received Mar 10, 2018 \\
Revised Feb 23, 2020 \\
Accepted Mar 2, 2020 \\
\hline Keywords: \\
Educational technology model \\
Information system success \\
System impact \\
System design \\
Technology acceptance model \\
System usage
\end{tabular}

System usage

\begin{abstract}
For distance learners, continuous official education is very important for improving knowledge and learning experience to meet the career challenges in the modern world. This work studies the success factors which affect the use of LMS and evaluates the ability to apply the proposed model in the field of distance learning (DL) particularly in higher education. The survey was carried out on higher education learners who were included in the DL instructions. This work has utilized a questionnaire that was modified from literature to inspect three measurements, system design, system usage, and system outcome. Utilizing the obtained survey data for students of DL $(\mathrm{N}=149)$, the path analysis discovered that the design of the system has a significant effect on the satisfaction of users and intention for using LMS which affects the use of the system. Consequently, the satisfaction of users and the system used has a great impact on the net benefit.
\end{abstract}

Copyright $@ 2020$ Institute of Advanced Engineering and Science. All rights reserved.

\section{Corresponding Author:}

Mutasem K. Alsmadi,

Department of Management Information Systems,

College of Applied Studies and Community Service,

Imam Abdulrahman Bin Faisal University,

Dammam, Saudi Arabia.

Email: mksalsmadi@gmail.com, mkalsmadi@iau.edu.sa

\section{INTRODUCTION}

Distance learning (DL) is one of the most important educational systems currently [1-6]. However, it is a very useful way for different learners' categories to get an education. People with different learning capacities, different ages, or those who are leaving far away from the education source could benefit from such type of systems. Moreover, it helps people who have lost their education chance, due to any social, economic, political or age reasons, to get a new chance to reach their goal. DL could be a very effective way to save costs for institutes, instructors and learners [7-9]. DL enables educational institutes to use media tools such as web-based media, videos, and audios effectively [10, 11].

Up to date studies in the field have introduced many advantages and disadvantages of using DL systems. The benefits of such systems lead to many higher education institutes to apply them to their programs and courses. DL has been integrated into the education process in many countries such as the United States and the United Kingdom a long time ago [12]. Saudi Arabian universities have joined such a growing wave of using DL [13]. Unfortunately, the existing DL systems still have many bugs and need more enhancements.one of the main advantages of using DL education in Saudi Arabian universities is to enable women to be involved in the higher education system effectively [14].

DL has been facilitated by the existence of the Internet. Students can attend the lectures and classes from anywhere and at any time if the lecture is open to access and has no time restrictions. Moreover, the Internet helps both instructors and students to access a larger variety of resources and information [12]. 
As the internet services improved in Saudi Arabia in the last decades, the use of DL has been encouraged by universities and higher education institutes. For the Saudi Arabian community, DL could play an important role in distributing education, especially among women [15]. The female student can balance her education process and taking care of her home. Moreover, some added expenses such as transportation from and to the university could be reduced. Not only individuals could benefit from the DL systems but also on the national level. It could help in improving the educational system quality and distribution and hence helps the kingdom in competing globally with other highly-ranked educational systems [14].

It is a must to improve the used DL systems in Saudi Arabia for many reasons. The increasing enrollment in the different educational programs, especially for women, is the most important factor [14]. Of course, the traditional education systems should be applied as well as the DL approach. A study performed by Al-Sultan has shown the increased enrollment of students as well as the number of denied higher education students. The study has clarified that in 1993, while 70000 students have been graduated, 2000 students were unable to proceed to higher education. However, in 2003, more than 200000 students have been graduated and almost 12000 students were unable to proceed to higher education [16]. As a conclusion of the study results, it has been shown that the ratio of higher education graduated students to the number of high school graduates is getting higher which leads to the necessity to give more focus to the problem [16].

Examples of Saudi universities that have applied the DL approach are King Saud University in Riyadh (KSU), King Abdulaziz University in Jeddah (KAU) and King Faisal University in Al-Hasaa (KFU). Previously, the DL systems were based on hard copied materials. Such materials were sent to the students via standard mail services. The mission of the three universities' DL programs is to utilize, integrate, and train students and faculty with the latest technology in DL [14]. Deanships of E-learning and DL have been established in the three universities to serve the main goal of DL and to accomplish their mission. In 2006, KAU has established the deanship while, in 2010, both KSU and KFU have established their deanships. The DL program in the three universities - as stated in their websites - is responsible for providing the students with online training materials and tools. Virtual classrooms concept has been introduced in their programs. In 2012, the University of Dammam (UOD) has developed its own e-learning and DL deanship and started its first programs in the field [14].

Artificial intelligence (AI) has been successfully used in many domains such as [17-27]. Recently; AI has been implemented in the LMS especially in fields like education, virtual learning, small -scale or large groups of users, corporate. Moreover; AI improved the training programs' effectiveness and provided precision and quality in educational processes [28-30].

In this work, we aim to evolve an effective LMS for the instruction of distance learning which is fully utilized and usable for administrators, instructors and students. It is not valuable to develop a good LMS if the success factors are unclear and the technology acceptance is low. Previously, the success factors and acceptance of the usage of LMS among stakeholders are investigated and resulted in the of the educational technology model (ETM) construction. Consequently, this work aims to verify and develop the integrity of an ETM which can be utilized as a guideline for developing or evaluating an LMS. The rest of the paper is organized as follows: Section 2 discussed the construction of ETM. Section 3 describes the research methodology. Section 4 illustrates the demographic information. Section 5 shows the measure of fit. Section 6 illustrates Hypotheses Testing. Section 7 is a discussion of the results. Section 8 is the conclusion of this paper.

\section{EDUCATIONAL TECHNOLOGY MODEL (ETM) CONSTRUCTION}

The model of the research was formed as a comparison outcome between the DL\&ML IS success model and the TAM model. The TAM model highlights gauging the user behavior by the professed utility and ease of use as the key in the use dimension variables and that will determine the system real use. This research reveals the value of evaluating the success of DL\&MS from an information systems viewpoint on the whole, and especially from the educational Technology viewpoint. Figure 1 contains the element and dimension of the proposed ETM.

\section{RESEARCH METHODOLOGY}

This research intends to confirm the planned success ETM by verifying Saudi student's success level toward the usage of LMS. A study is performed on a trail from 6 Saudi universities of around 149 students who use the LMS platform and provided DL program University of Dammam, King Faisal University, King Abdulaziz University, Saudi Electronic University Arab Open University and University of Imam Muhammad bin Saud. The investigators have used survey technique, and to all students enrolled in the DL 
section from those 6 Saudi universities' feedback forms is circulated. The feedback form is developed derived from questions mentioned by former studies and investigators, in addition to points stated in the literature associated with ETM dimensions. To see if the outcome of this study is reliable with previous literature, the investigator attempted to go with certain things with LMS concerns. Things are measured by the use of five point-Likert-scales which range from strongly agree to strongly disagree. Approximately 15 minutes were taken by respondents to finish the questionnaire. Respondents were guaranteed that their personal responses will be secret. To study the information and use AMOS 18 for theories testing and to find out the model match by way of structural equation model (SEM) the researchers used Statistical Package for the social sciences (SPSS) 17.0.

This instrument validity was evaluated by way of revision of the questionnaire, pre-testing, and content validity. The construction and matter of the questionnaire were even assessed by 2 critics. The critics are professors in the sphere of Instructional Technology, at the University of Dammam, King Faisal University, King Abdulaziz University, Saudi Electronic University Arab Open University and University of Imam Muhammad bin Saud. The investigators then carry out a consistency test for every construct to evaluate the measures' reliability and goodness. Table 1 by Sekaran [31] reveals the high consistency of every construct as stated.

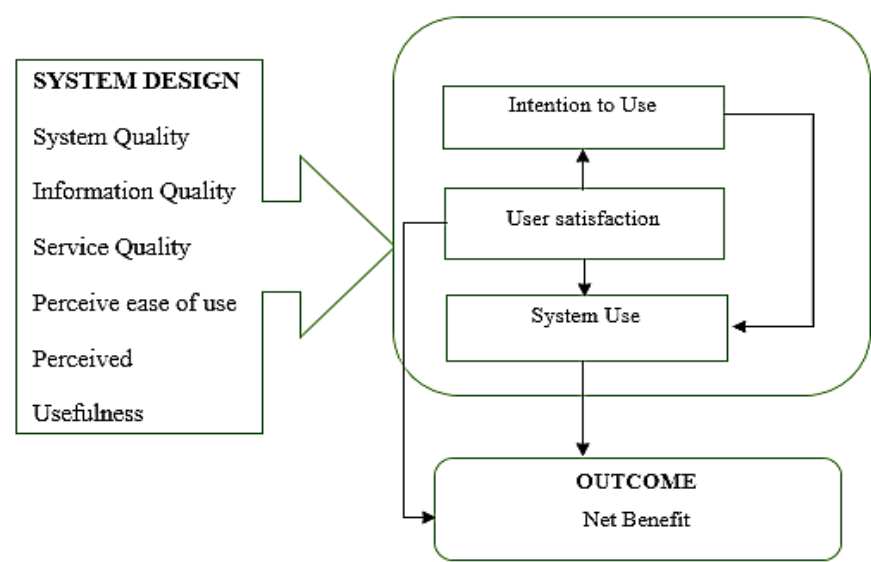

Figure 1. The main elements of the proposed ETM

Table 1. Cronbach's alpha

\begin{tabular}{ll}
\hline Item Reliability & Item Reliability \\
\hline Net benefit & 0.803 \\
User satisfaction & 0.845 \\
Service quality & 0.890 \\
System quality & 0.944 \\
Perceived usefulness & 0.914 \\
Information quality & 0.919 \\
System use & 0.954 \\
Perceived ease of use & 0.892 \\
Intention to use & 0.822 \\
\hline
\end{tabular}

\section{DEMOGRAPHIC DATA}

Table 2 shows the synopsis of the background information. It could be observed that 75.2 percent of the respondents are women while 24.8 percent of them are men. Most of the respondents aged twenty to forty years old. Around 22.81 percent of the respondents have used a computer for more than 10 years and most have used a computer for over one year. For over 1 year all of them know using LMS.

\section{MEASURE OF FIT}

The projected research model includes the IS success model and the features of the technology acceptance model. The model offers 4 endogenous variables (BI, USE, SAT, NB,) and 5 exogenous or observed variables (SVQ, PU, PEU, SYQ, INQ,). After modification and testing, the model is known as the ETM all through the remaining of this study. 
The CFA is performed using AMOS 18 SEM software. The CFA aims to build a structural model that arranges the tested measures to the individual builds, by limiting the inconsistency of every measure to the hidden build it must signify. Besides evaluating the amount to which every measure adds to its dormant construct, the CFA even checks the division among constructs by assessing the appropriate in the on the whole model. Table 3 shows the measures of fit.

Table 2. Demographic data

\begin{tabular}{lll}
\hline Gender & Frequency & Percent \\
\hline Male & 37 & 24.8 \\
Female & 112 & 75.2 \\
Age & Frequency & Percent \\
$20-24$ & 91 & 61.1 \\
$25-29$ & 24 & 16.1 \\
$30-40$ & 27 & 18.1 \\
$41-50$ & 6 & 4.0 \\
Over 50 & 1 & 0.7 \\
Computer Usage & Frequency & Percent \\
less than 1 year & 20 & 13.42 \\
1-3 year & 30 & 20.13 \\
3-7 years & 40 & 26.84 \\
7-10 years & 25 & 16.77 \\
more than 10 years & 34 & 22.81 \\
LMS Usage & Frequency & Percent \\
less than 1 year & 30 & 20.13 \\
1-3 year & 60 & 40.26 \\
3-7 years & 45 & 30.20 \\
7-10 years & 13 & 8.72 \\
more than 10 years & 1 & 0.67 \\
Total & 149 & 100 \\
\hline
\end{tabular}

Table 3. The used fit measures

\begin{tabular}{lll}
\hline Fit Measures & Standards Fit & Model Fit \\
\hline CMIN/Df & A value near 1 and not more than 3 represents a good fit. & 2.800 \\
P Value & A P value of more than 0.005 represents an acceptable fit. & 0.022 \\
RMSEA & A value that doesn't exceed 0.1. & 0.490 \\
TLI & A value near 1 represents a very good fit. & 0.986 \\
CFI & A value near 1 represents a very good fit. & 0.996 \\
GFI & A value equal to or fewer than 1 represents a perfect fit. & 0.989 \\
AGFI & A value equal to or fewer than 1 represents a perfect fit. & 0.953 \\
RMR & RMR of fewer than 0.05 represents a perfect fit. & 0.016 \\
IFI & IFI values near 1 represent a very good fit. & 0.996 \\
RFI & RFI values near 1 represent a very good fit. & 0.973 \\
NFI & TLI values near 1 represent a very good fit. & 0.992 \\
\hline
\end{tabular}

\section{HYPOTHESES TESTING}

To try out a set of hypotheses at the same time in the way of a model with considerable level 0.05 structural equation modeling is properly suitable. However, it assists to show these hypotheses and to reflect on everyone separately. From Table 4, the hypotheses which explain the association among the dependent variable (BI, SAT,) and independent variables (PU, SvQ, InQ, PEU, SyQ,) are important excluding the association among BI and InQ. It reveals that PEU, SyQ, PU, InQ, SvQ, have extensively effect PU, SAT, PEU, SvQ, and SyQ, which have considerably affected BI. It even reveals that the SAT has a major link with NB, USE, and BI. However, BI has an important association with USE, and USE considerably affects NB. There is enough proof linked with the causal association among dependent variables and independent variables in the model that assists the effort to know the dynamics among the constructs. The studies reveal that PEU and PU are correlated as forecasted in the hypothetical task.

The basis for such a connection in the associations is possible owing to the higher phase of implementation and constant usage of expertise. Therefore, the AMOS Modification Indices 18 advises the independent variable to be interrelated; Table 5 reveals the independent variables correlation result. This research establishes that there is a great major correlation among TAM independent variables and the DL\&ML quality dimensions. This judgment validates additional study suggested by Ultan et al., [32] that recommended to additional look at the interdependency of the aspects of success and quality and the correlations among aspects. In Table 5 a correlation analysis reveals a positive correlation in ETM among independent variables (i.e. information quality, service quality, system quality, perceived ease of use and 
perceived usefulness). Every construct reveals bigger variation with its own group of signs than with the different constructs signifying a diverse array of signs.

Table 4. Hypotheses of the ETM [33]

\begin{tabular}{ccccccc}
\hline \multicolumn{6}{c}{ No. } & \multicolumn{6}{c}{ Hypotheses } & Reference & Effect & $\beta$ & Sig \\
\hline 1 & PU & SAT & {$[34]$} & Supported & 0.254 & $* * *$ \\
2 & SvQ & SAT & {$[35]$} & Supported & 0.254 & $* * *$ \\
3 & InQ & SAT & {$[35]$} & Supported & 0.211 & $* * *$ \\
4 & SyQ & SAT & {$[35]$} & Supported & 0.236 & $* * *$ \\
5 & PEU & SAT & {$[34]$} & Supported & 0.084 & .036 \\
6 & PEU & BI & {$[36]$} & Supported & 0.102 & .019 \\
7 & PU & BI & {$[36]$} & Supported & 0.382 & $* * *$ \\
8 & SvQ & BI & {$[35]$} & Supported & 0.126 & .009 \\
9 & InQ & BI & {$[35]$} & Not Supported & -0.169 & $* * *$ \\
10 & SyQ & BI & {$[35]$} & Supported & 0.149 & $* * *$ \\
11 & SAT & BI & {$[35]$} & Supported & 0.339 & $* * *$ \\
12 & BI & USE & {$[35]$ and [36] } & Supported & 0.145 & .045 \\
13 & SAT & USE & {$[35]$} & Supported & 0.150 & .038 \\
14 & SAT & NB & {$[35]$} & Supported & 0.479 & $* * *$ \\
15 & USE & NB & {$[35]$} & Supported & 0.135 & .002 \\
\hline
\end{tabular}

Table 5. Correlations between independent variables

\begin{tabular}{cc}
\hline & Estimate \\
\hline PU <--> SyQ & 0.559 \\
SvQ <--> PEU & 0.558 \\
InQ <--> PEU & 0.470 \\
SvQ <--> SyQ & 0.703 \\
InQ <--> SyQ & 0.621 \\
PU <--> SvQ & 0.632 \\
SvQ <--> InQ & 0.755 \\
SyQ <--> PEU & 0.491 \\
PU <--> PEU & 0.791 \\
PU <--> InQ & 0.598 \\
\hline
\end{tabular}

\section{DISCUSSION}

The assessment of the LMS is vital to make sure of their useful execution and positive influence on DL distribution. A lot of institutes realize that it's very simple, to begin with, a commercial LMS, however, they come across a lot of issues, for instance, suitability to target users, assessment tools, linguistic, and pricing. An LMS assessment research that was performed showed that the upgrading of the present system is essential. To fulfill this necessity, the latest framework is launched for the assessment of IS in instructive settings. The projected ETM framework with 3 features was built after having analytically assessed the current findings of acceptance studies and IS success. ETM is build founded on past models of IS assessment, particularly, IS Achievement model and the TAM. The authors integrate the initiative of fit amongst technology design quality, Use and system result (net gain).

The paper summarizes the methodology of the review method using information from Structural Equation Modeling (SEM) analysis and distance learners $149(\mathrm{~N}=149)$. The key findings of the study are the recognition of the factors which decide the success and use of the educational technology system. Derived from such aspects we invent a measurement model to confirm the associations amongst IS and TAM success elements. Because of the changes in the technology the user needs are changed. Thus; there is a need for more LMS improvements and enhancements from time to time [37] in order to meet the user needs and requirements. The proposed prototyping system was developed based on the needs of the students, instructors, and administrators in the DL universities which are called SLMS. This work integrated 20 features to the current LMS features that were required by the SLMS users. The prototyping system concentrated on the important and required features by the distance learners such as:

- System appointment,

- Book-sharing system,

- Experience-sharing system,

- Tools for publishing learners,

- Chat room, plagiarism detection,

- Video conversation,

- Online surveys,

- Social networks.

The students' acceptance of learning management systems in Saudi Arabian.... (Mutasem K. Alsmadi) 


\section{CONCLUSION}

This research has verified and constructed an instructive technology success model. By means of LMS as a hypothetical background, we build 3 measures in system usage 5 measures in system design quality and net profit in system result as instructive technology success elements. The experiential outcome offers suitable support for the model. Nearly all theorized relations were observed to be important. The present LMS study thinks about the success dimensions as system information service, information quality, behavioral intent to usage, usefulness, ease of use, system use and user contentment to affect the net gain. Therefore, the developed ETM respects causal effects and the interrelationships between the key elements of the measure: system use, system design and system result (net profits). All other aspects of system design excluding information quality have a direct impact on the behavioral intent of usage. Besides, user satisfaction and behavioral intent to use have a direct influence on system usage. However, user satisfaction and system use have a positive impact on net gain.

\section{REFERENCES}

[1] Simpson O., "Supporting students in online, open and distance learning," Routledge, 2018.

[2] Simonson M., S. M. Zvacek, and S. Smaldino, "Teaching and Learning at a Distance: Foundations of Distance Education 7th Edition," IAP, 2019.

[3] Nurakun Kyzy, Z., R. Ismailova, and H. Dündar, "Learning management system implementation: a case study in the Kyrgyz Republic," Interactive Learning Environments, vol. 26, no. 8, pp. 1010-1022, 2018.

[4] Bell S., et al., "Sustainability and distance learning: a diverse European experience?," Open Learning: The Journal of Open, Distance and E-Learning, vol. 32, no. 2, pp. 95-102, 2017.

[5] Samigulina G. and A. Shayakhmetova, "The information system of distance learning for people with impaired vision on the basis of artificial intelligence approaches," in Smart Education and Smart e-Learning, pp. 255-263, 2015.

[6] Song D., E. Y. Oh, and M. Rice, "Interacting with a conversational agent system for educational purposes in online courses," in 2017 10th international conference on human system interactions (HSI), 2017.

[7] Isman A., Barkan M., and Ugur D., "Distance Education," Online Distance Education Book: The Turkish Online Journal of Educational Technology, 2017. [Online]. Available: http://www.icde.org/en/resources/reports/

[8] Van Lieshout M., T. M. Egyedi, and W. E. Bijker, "Social Learning Technologies: The introduction of multimedia in education," Routledge, 2018.

[9] Astuti I. A. D., D. Dasmo, and N. Nurullaeli, "The Use of Pocket Mobile Learning to Improve Critical Thinking Skills in Physics Learning," International Journal of Recent Contributions from Engineering, Science \& IT (iJES), vol. 6, no. 4, pp. 80-86, 2018 .

[10] CDLP, "What is Distance Learning?," California Distance Learning Project, 2018. [Online]. Available: http://www.cdlponline.org/index.cfm?fuseaction=about

[11] Devi K.S., E.Gouthami, and V. V. Lakshmi, "Role of Social Media in Teaching-Learning Process," Journal of Emerging Technologies and Innovative Research, vol. 6, no. 1, pp. 96-103, 2019.

[12] McIsaac M. S. and C. N. Gunawardena, "Distance education. Handbook of research for educational communications and technology," Routledge, pp. 403-437, 1996.

[13] Aljaber A., "E-learning policy in Saudi Arabia: Challenges and successes," Research in Comparative and International Education, vol. 13, no. 1, pp. 176-194, 2018.

[14] Aljabre A., "An exploration of distance learning in Saudi Arabian universities: Current practices and future possibilities," International Journal of Instructional Technology and Distance Learning, vol. 9, no. 2, pp. 21-28, 2012.

[15] Badwelan A. and A. A. Bahaddad, "Cultural Factors that Influence M-Learning for Female University Students: A Saudi Arabian Case Study," International Journal of Computer Applications, vol. 166, no. 5, pp. 21-32, 2017.

[16] Altowajry A., "Reforming higher education in Saudi Arabia: The use of telecommunications technology," Thesis, RIT, 2005. [Online]. Available at: https://ritdml.rit.edu/bitstream/handle/1850/926/AAltowjryThesis2005.pdf.

[17] Alsmadi M. K., "Content-Based Image Retrieval Using Color, Shape and Texture Descriptors and Features," Arabian Journal for Science and Engineering, pp. 1-14, 2020.

[18] Eljawad L, Aljamaeen R, Alsmadi M K, Al-Marashdeh I, Abouelmagd H, Alsmadi S, Haddad F, Alkhasawneh RA, Alzughoul M and Alazzam M B., "Arabic Voice Recognition Using Fuzzy Logic and Neural Network," International Journal of Applied Engineering Research, vol. 14, no. 3, pp. 651-662, 2019.

[19] Alsmadi M K, Tayfour M, Alkhasawneh R A, Badawi U, Almarashdeh I and Haddad F., "Robust feature extraction methods for general fish classification," International Journal of Electrical \& Computer Engineering (IJECE), vol. 9, no. 6, pp. 5192-5204, 2019.

[20] Alsmadi M. K., "Hybrid Genetic Algorithm with Tabu Search with Back-Propagation Algorithm for Fish Classification: Determining the Appropriate Feature Set," International Journal of Applied Engineering Research, vol. 14, no. 23, pp. 4387-4396, 2019.

[21] Alsmadi M. K., "Facial expression recognition," 2018.

[22] Al-Marashdeh I, Jaradat G M, Ayob M, Abu-Al-Aish A and Alsmadi M., "An Elite Pool-Based Big Bang-Big Crunch Metaheuristic for Data Clustering," Journal of Computer Science, vol. 14, no. 12, pp. 1611-1626, 2018. 
[23] Almarashdeh I, Alsmadi M K, Jaradat G, Althunibat A, Albahussain S A, Qawqzeh Y, Badawi U A, Farag T and Eldaw K E., "Looking Inside and Outside the System: Examining the Factors Influencing Distance Learners Satisfaction in Learning Management System," Journal of Computer Science, 2018.

[24] Alsmadi M K., "An efficient similarity measure for content based image retrieval using memetic algorithm," Egyptian Journal of Basic and Applied Sciences, vol. 4, no. 2, pp. 112-122, 2017.

[25] Alsmadi M K., "Query-sensitive similarity measure for content-based image retrieval using meta-heuristic algorithm," Journal of King Saud University - Computer and Information Sciences, 2017.

[26] Alsmadi M K., "Forecasting River Flow in the USA Using a Hybrid Metaheuristic Algorithm with BackPropagation Algorithm," Scientific Journal of King Faisal University (Basic and Applied Sciences), vol. 18, no. 1, pp. 13-24, 2017.

[27] Alsmadi M., "Facial recognition under expression variations," Int. Arab J. Inf. Technol., vol. 13, no. 1A, pp. 133-141, 2016.

[28] Alharbi M and Jemmali M., "Artificial intelligent e-learning architecture," In Ninth International Conference on Machine Vision (ICMV 2016), pp. 103412G, 2016.

[29] Cavus N., "The evaluation of Learning Management Systems using an artificial intelligence fuzzy logic algorithm," Advances in Engineering Software, vol. 41, no. 2, pp. 248-254, 2010.

[30] Sivakumar S, Venkataraman S and Gombiro C., "A user-intelligent adaptive learning model for learning management system using data mining and artificial intelligence," 2015.

[31] Sekaran U. and R. Bougie, "Research methods for business: A skill building approach," John Wiley \& Sons, 2016.

[32] Sharkey U., M. Scott, and T. Acton, "The influence of quality on e-commerce success: an empirical application of the Delone and Mclean IS success model," International Journal of E-Business Research (IJEBR), vol. 6, no. 1, pp. 68-84, 2010.

[33] Almarashdeh I A, Sahari N, Zin N a M and Alsmad M., "The Success of Learning Management System Among Distance Learners in Malaysian Universitie," Journal of Theoretical and Applied Information Technology, vol. 21, no. 2, pp. 80-91, 2010.

[34] Alhelalat J, Ineson E M, Jung T and Evans K., "The Evaluation of Hotel Websites' Quality, Usability and Benefits: Developing a Testing Model," In Proceedings of Euro-CHRIE Conference, 2008.

[35] Delone W H and McLean E R., "The DeLone and McLean model of information systems success: a ten-year update," Journal of management information systems, vol. 19, no. 4, pp. 9-30, 2003.

[36] Davis F D., "Perceived usefulness, perceived ease of use, and user acceptance of information technology," MIS Quarterly, pp. 319-340, 1989.

[37] Almarashdeh I., et al., "Development of an interactive learning management system for malaysian distance learning institutions," Middle East Journal of Scientific Research, vol. 14, no. 11, pp. 1471-1479, 2013. 